\title{
Long-term Outcome of a Fissurectomy: A Prospective Single-Arm Study of 50 Operations out of 349 Initial Patients
}

\author{
Jean-David Zeitoun ${ }^{1,2}$, Pierre Blanchard ${ }^{3}$, Nadia Fathallah $^{4}$, Paul Benfredj $^{4}$, Nicolas Lemarchand ${ }^{4}$, \\ Vincent de Parades ${ }^{4}$ \\ ${ }^{1}$ Proctologie Médico-Interventionnelle, Groupe Hospitalier Diaconesses - Croix-Saint-Simon, Paris; ${ }^{2}$ Gastroentérologie et Nutrition, Hôpital \\ Saint-Antoine, Paris; ${ }^{3}$ Service de Biostatistiques et d'Epidémiologie, Institut Gustave Roussy, Villejuif; ${ }^{4}$ Proctologie Médico-Chirurgicale, \\ Institut Léopold Bellan, Groupe Hospitalier Paris Saint-Joseph, Paris, France
}

Purpose: The surgical standard of care for patients with chronic anal fissure is still disputed. We aimed to assess the natural course of idiopathic anal fissure and the long-term outcome of a fissurectomy as a surgical treatment.

Methods: All consecutive patients referred to a single expert practitioner in a tertiary centre were primarily included. A fissurectomy was proposed in cases of refractory symptoms after 4 to 6 weeks of standard medical management. Only patients with idiopathic and noninfected anal fissures were included in this second subsample to undergo surgery. Conventional postoperative management was prescribed for all patients who had undergone surgery. The main outcome measures were the success rate (defined as a combination of wound healing and relief of pain) and postoperative anal continence. Results: Three hundred forty-nine patients were primarily recruited. Fifty patients finally underwent surgery for an idiopathic and noninfected fissure. Among them, 47 (94\%) were cured at the end of primary follow-up, and 44 of the 47 (93.6\%) could be confirmed as being sustainably cured in the longer-term follow-up. The mean time of complete healing was 10.3 weeks (range, 5.7-36.4 weeks). All patients were free of pain at weeks 42 . The continence score after surgery was not statistically different from the preoperative score.

Conclusion: A fissurectomy for the treatment of patients with an idiopathic noninfected fissure is associated with rapid pain relief and a high success rate even though complete healing may often be delayed. Moreover, it appears to have no adverse effect on continence.

Keywords: Anal fissure; Fissurectomy; Anal continence

\section{INTRODUCTION}

Anal fissure is one of the most frequent anal conditions. Sphincter hypertonia engendering local ischemia is considered as the main causal mechanism. Medical management is to be offered as a pri-

Received: February 12, 2017 - Accepted: June 12, 2017

Correspondence to: Jean-David Zeitoun, M.D.

Groupe Hospitalier Diaconesses Croix Saint-Simon, 125, rue d'Avron, 75020, Paris, France

Tel: +33 6083171 62, Fax: +33144643317

E-mail: jdzeitoun@yahoo.fr

ORCID code: https://orcid.org/0000-0001-9590-3461

(C) 2018 The Korean Society of Coloproctology

This is an open-access article distributed under the terms of the Creative Commons Attribution NonCommercial License (http://creativecommons.org/licenses/by-nc/4.0) which permits unrestricted noncommercial use, distribution, and reproduction in any medium, provided the original work is properly cited. mary approach, with treatment of constipation being a mainstay of conservative therapy. However, when symptoms persist after 4 to 8 weeks of appropriate medical treatment, surgery should be considered. The lateral internal sphincterotomy remains the technique of choice for many practitioners, which is supported by good empirical evidence and by recommendations of scientific societies $[1,2]$. It reduces the hypertonia by decreasing the pressure in the anal canal, thereby improving local vascularization and allowing the fissure to resolve. The results display an average $90 \%$ rate of healing and a recurrence rate below $10 \%[2,3]$. Nevertheless, the procedure is associated with anal incontinence rates up to $30 \%$ in some studies [4]. Therefore, alternative techniques have been proposed, but are considered as being associated with a lower level of evidence. Among those techniques are the 'tailored' lateral sphincterotomy [5], pneumatic balloon dilation [6], and 


\section{Coloproctology Jean-David Zeitoun, et al.}

foremost surgical techniques that do not divide the internal anal sphincter, namely, a subcutaneous fissurotomy [7], fissurectomy $[8,9]$ and fissurectomy associated with anoplasty, the so-called V-Y cutaneous flap [10] or mucosal flap [9, 11]. Many authors initially offered those techniques to patients with high risk of postoperative incontinence, such as elderly people, multiparous women, patients with normal anal tone, patients with chronic diarrhea of any origin, and patients who had undergone previous anorectal surgery. Because the results exhibited similar rates of healing as compared to those obtained with a lateral internal sphincterotomy, both in anecdotal and published evidence, many proctologists, especially those in France, adopted those sphinctersparing techniques as a standard care for any chronic anal fissure refractory to medical management. This is the case in our tertiary center where the fissurectomy is the most proposed technique for a chronic anal fissure. In this report, we aim to describe the natural history of anal fissure in a cohort of patients referred to our center and foremost to assess the long-term results of a fissurectomy in patients undergoing this operation.

\section{METHODS}

All consecutive patients with idiopathic anal fissure referred to a single expert proctologist at our tertiary center from October 2008 through October 2011 were recruited in the primary cohort. All of them were initially managed according to the same conservative standard protocol, namely, medical treatment including laxative agents for constipation or loperamide for diarrhea, pain killers tailored to the visual analogue scale, and local ointments. All patients were assessed 4 to 6 weeks after the first visit, and surgical treatment was offered in the case of refractory symptoms. Patients with infected fissures were secondarily excluded. Patients with other significant proctologic conditions were also not included in the final study sample.
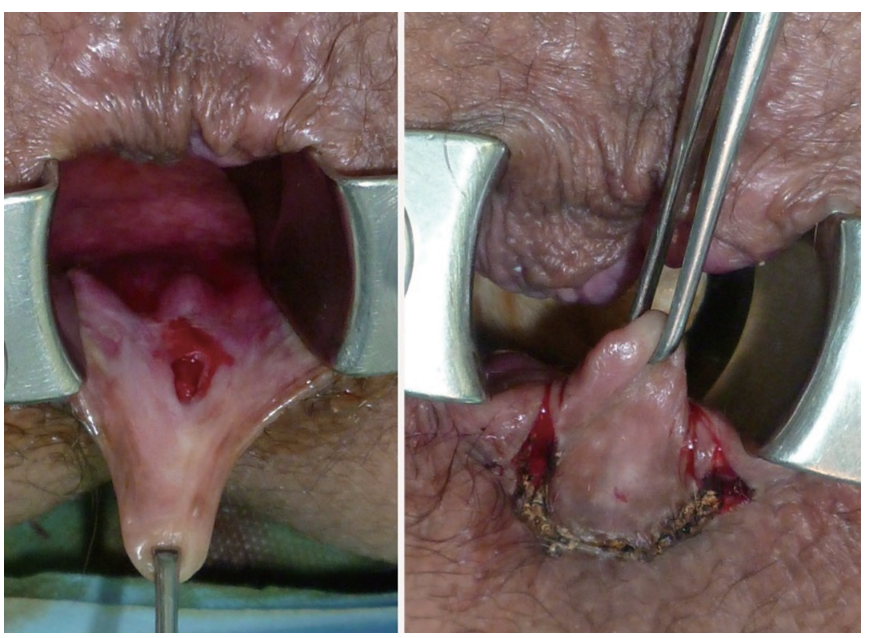

Fig. 1. Intraoperative view of a fissurectomy.
All patients that accepted surgery according to the indication defined above underwent surgery in the lithotomy position under general or spinal anesthesia. Prophylactic parenteral antibiotics were administered just before the procedure according to a standardized protocol. The fissurectomy was performed using an electric scalpel, with the dissection starting by an incision of the anal verge below the edge of the fissure, then surrounding it, and eventually going above the dentate line (Fig. 1). Any associated skin tag was removed within the same piece of tissue. Hemostasis was achieved as needed, and the wound was left open (Fig. 2). Patients were discharged on the same day, and all of them were given a standard prescription for laxatives and local ointment so as to lubricate the anal canal and foremost to maintain its elasticity and avoid stenosis.

Patients were seen in the clinic every 2 weeks after discharge. The main outcome measures were the success rate and postoperative anal continence. Treatment was considered successful if the patient was painless and the wound was healed. Continence was assessed by using the Wexner score [12] both in the preoperative setting and after surgery. Final data were reviewed by an independent observer according to a pre-established questionnaire.

In France, the fissurectomy has been the standard of care for a chronic anal fissure for a long time; therefore, this study did not require any authorization from an ethics committee according to French ethics law. Nevertheless, all patients gave written informed consent to be included. This study was submitted to the French National Commission for Data Protection (Commission Nationale Informatique et Libertés), and a guarantee was given that data would be kept anonymous and confidential.

All procedures performed in studies involving human participants were in accordance with the ethical standards of the institu-

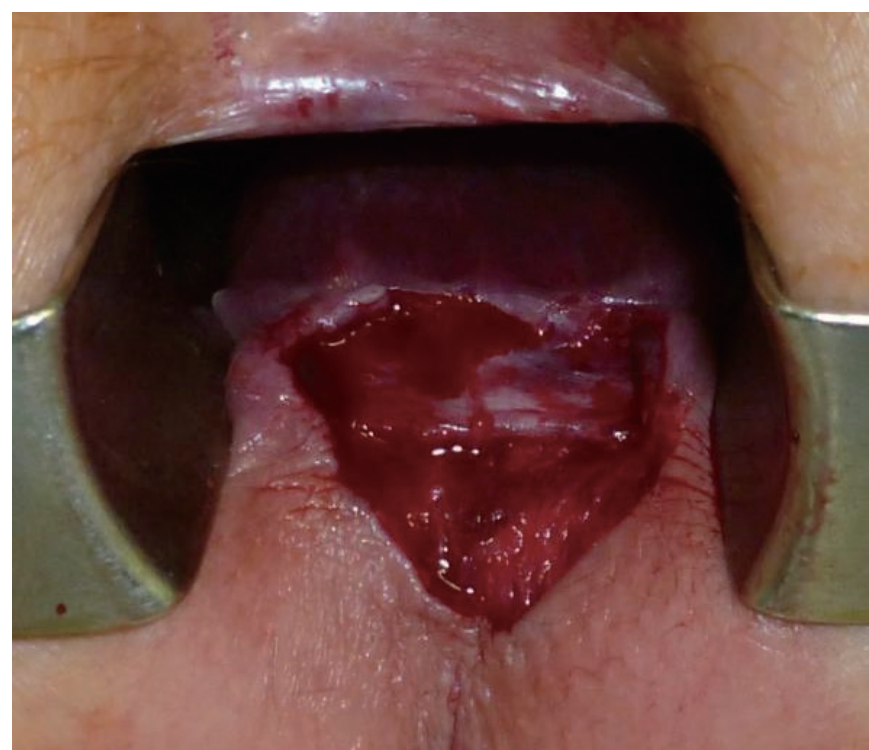

Fig. 2. Postoperative view of the wound. 
tional and/or national research committee and with the $1964 \mathrm{Hel}-$ sinki declaration and its later amendments or comparable ethical standards. This study was performed in accordance with French ethics law. All patients gave written informed consent to be included.

All statistical analyses were performed with SAS ver. 9 (SAS In-

Table 1. Patients' characteristics at the different stages of the study (n = 349)

\begin{tabular}{|c|c|}
\hline Characteristic & Value \\
\hline \multicolumn{2}{|l|}{ Initial sample of 349 patients } \\
\hline Age (yr) & $44.9(16-87)$ \\
\hline Men & $184(52.7)$ \\
\hline Posterior location & $289(82.8)$ \\
\hline Anterior location & $42(12)$ \\
\hline Both posterior and anterior location & $18(5.2)$ \\
\hline \multicolumn{2}{|l|}{ Surgery sample $(n=50 ; 14.3)$} \\
\hline Age (yr) & $42.3(16-87)$ \\
\hline Men & $31(62)$ \\
\hline Posterior location & $45(90)$ \\
\hline Anterior location & $5(10)$ \\
\hline Smoking & $9(64.3)$ \\
\hline Previous history of proctologic surgery & $5(10)$ \\
\hline Time lag from fissure onset (wk) & $84(2.1-622.7)$ \\
\hline $\begin{array}{l}\text { Preoperative anal hypertonia at digital rectal } \\
\text { examination }\end{array}$ & $41(82)$ \\
\hline \multicolumn{2}{|l|}{ Surgical indication } \\
\hline Failure of medical management & $41(82)$ \\
\hline Recurrence after treatment discontinuation & $9(18)$ \\
\hline \multicolumn{2}{|l|}{ Intraoperative features } \\
\hline \multicolumn{2}{|l|}{ Type of anesthesia } \\
\hline Spinal & $33(66)$ \\
\hline General & $17(34)$ \\
\hline \multicolumn{2}{|l|}{ Postoperative and follow-up data } \\
\hline Clinical follow-up (wk) & $15.9(4.3-62.6)$ \\
\hline \multicolumn{2}{|l|}{ Initial outcome } \\
\hline Initial cure & $47(94)$ \\
\hline Initial failure & $2(4)$ \\
\hline Loss of follow-up & $1(2)$ \\
\hline \multicolumn{2}{|l|}{ Long-term outcome } \\
\hline Long-lasting cure & $44(88)$ \\
\hline Recurrence & $3(6)$ \\
\hline Time before wound healing (wk) & $10.3(5.7-36.4)$ \\
\hline Pain relief at week 42 & $50(100)$ \\
\hline
\end{tabular}

Values are presented as mean (range) or number (\%). stitute, Cary, NC, USA). Continuous data are given as means (standard deviations) or medians (ranges), and categorical data as the numbers of observations and the ratios.

\section{RESULTS}

Three hundred forty-nine consecutive patients were seen by the principal investigator for an anal fissure during the study period as described above. Demographics and clinical characteristics are presented in Table 1. Fig. 3 displays the flow chart leading to the final sample of 50 patients solely operated on by using a fissurectomy and eventually assessed.

Among the 50 patients that underwent surgery and were assessed in the final sample, 47 were cured at the end of the primary follow-up (94\%). The mean time for obtaining wound healing was $10.3 \pm 4.96$ weeks. All patients were free of pain at day 42 . Two patients (4\%) were classified as fissurectomy failures: one due to nonhealing and one related to a postoperative intersphincteric fistula that needed a reoperation. One patient (2\%) was lost to follow-up. Among the 47 patients described above, 44 (93.6\%) were considered as sustainably cured, which was confirmed through long-term telephone calls (median time, 11.7 months from the end of healing; range, 5.7-15.2), and 3 (6.4\%) experienced fissure recurrence that was successfully managed through medical treatment.

Detailed data regarding the preoperative and the postoperative

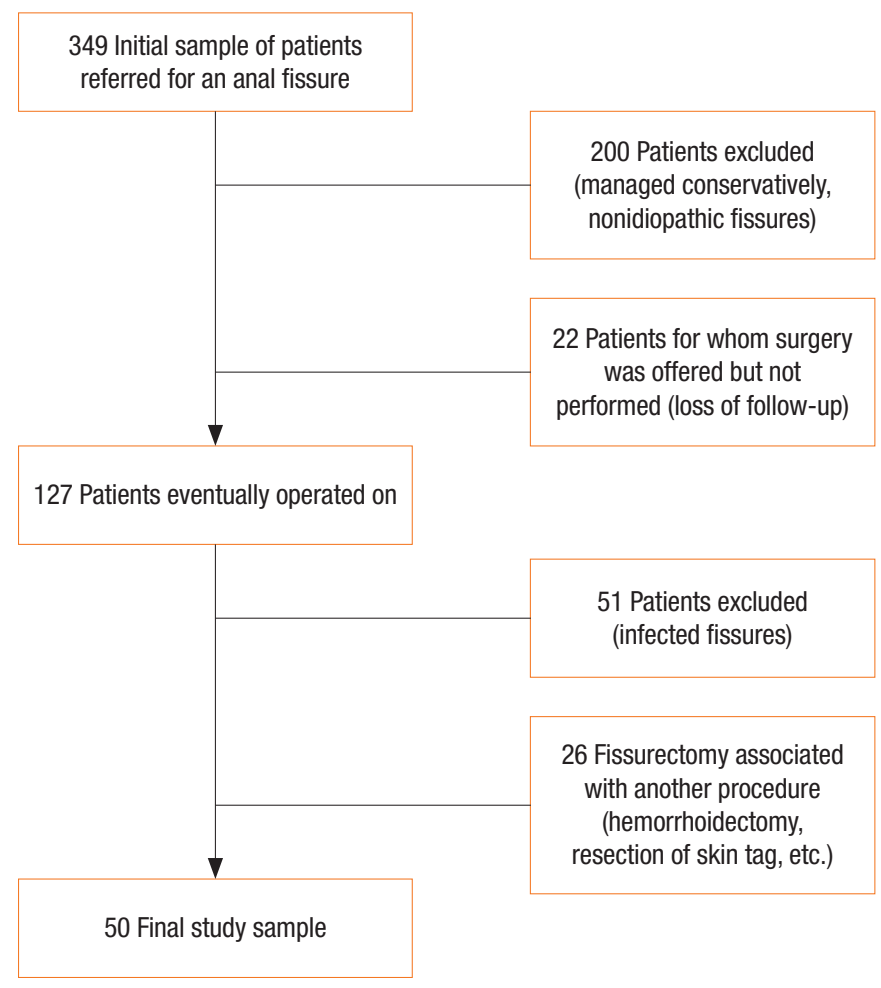

Fig. 3. Study flow chart. 
Table 2. Comparison of pre- and postoperative continence

\begin{tabular}{lc}
\hline Continence data & Value \\
\hline Preoperative Wexner score & $0(0-0)$ \\
Postoperative Wexner score & $0.8(0-2)$ \\
Patients with unchanged Wexner score after surgery & $47(94)$ \\
\hline
\end{tabular}

Values are presented as mean (range) or number (\%).

Wexner scores are presented in Table 2. In summary, 47 patients among the 50 that underwent surgery did not see any change in their Wexner scores, and the 2 remaining patients that could be assessed had a postoperative Wexner score of 2 . Overall, when the whole sample of patients was considered, the continence score after surgery was not statistically different from that before surgery.

\section{DISCUSSION}

In our study of 50 patients operated on by using a fissurectomy for chronic idiopathic anal fissure over a 4 -year period, we found that the cure rate was high, that relief of pain was quickly obtained, and that postoperative continence was unaffected by the surgery. Our study has several strengths as compared to previous studies. First, the study involved a prospective cohort, and the overall clinical pathway followed by the patients from diagnosis of the anal fissure to the operation and its outcome could be recorded. Second, a careful selection was made so as to lead to a homogeneous cohort of patients with idiopathic anal fissures, and all patients undergoing the fissurectomy were operated on by a single expert practitioner, thereby enhancing the internal validity of our study. Late follow-up and data collection were performed by an independent observer.

Our findings raise several important issues worth considering about fissure management. First, our operation rate was low as compared to most operation rates in similar reports in the scientific literature. Eventually, about $15 \%$ of the patients were solely operated on for a chronic idiopathic and noninfected anal fissure refractory to medical management whereas most authors state an intervention rate of approximately $50 \%$. Second, our healing rate was high. This is likely to revive the debate regarding the place of alternative techniques to the lateral internal sphincterotomy in the modern therapeutic strategy. Even though our technique was associated with delayed complete healing, of note is that pain relief, which is the outcome relevant to the patients, was substantially faster. This finding is consistent with those in prior reports [13]. Third, no significant deleterious effect on anal continence was observed. This latter finding is another argument relevant to the controversy about the surgical treatment of choice. Indeed, the most notable negative impact of the lateral internal sphincterotomy is its mid- and long-term risk of incontinence, which, although variably measured, has been repeatedly found to be substantial in many series and whose management is frequently tricky. Therefore, the fact that the fissurectomy seems unlikely to alter continence should actually be considered as a strength of this technique.

Our findings regarding the effectiveness of the fissurectomy are consistent with the results found in other analogous reports. Most comparative studies with the lateral internal sphincterotomy also showed similar outcomes [13-16]. Therefore, we argue that now a substantial body of evidence exists supporting the use of this technique alternatively to the lateral internal sphincterotomy because of its favorable benefits-risk balance. We recognize that the lateral internal sphincterotomy still has advantages over the fissurectomy, such as the speed of recovery, the absence of pain in most patients, and its effectiveness. Nevertheless, we believe that the associated risk of continence disorders is not acceptable given the benign status of the condition of origin, the existence of reliable alternative techniques, and the almost incurable status of postoperative incontinence. We argue that, at least, the choice should be offered to patients within the frame of the decision-making process. Lastly, personal observation suggests that the intraoperative use of an anal retractor is likely to engender a certain degree of dilatation of the anal canal, thereby providing immediate pain relief and partly addressing the pathophysiology of the anal fissure. This is also supported by previous reports [17].

Our study has several limitations. First, it is a noncontrolled study, so direct comparison with the technique of reference is not possible. Second, many patients of the initial sample were finally excluded from the analysis; nevertheless, that allowed us to study a highly homogeneous sample of patients treated with a fissurectomy. Last, although we rigorously evaluated preoperative and postoperative continence through a recognized benchmark score, we failed to assess the quality of life before and after surgery.

We found that a fissurectomy indicated for a chronic idiopathic anal fissure is associated with a rapid relief of anal pain, a high healing rate, and a lack of deleterious consequences on anal continence. Those findings provide some reassurance that a chronic anal fissure can, indeed, be cured with an acceptable postoperative course and no substantial risk to continence. The fissurectomy should be fully incorporated in the current surgical armamentarium for the management of patients with an anal fissure.

\section{CONFLICT OF INTEREST}

No potential conflict of interest relevant to this article was reported.

\section{REFERENCES}

1. Cross KL, Massey EJ, Fowler AL, Monson JR; ACPGBI. The management of anal fissure: ACPGBI position statement. Colorectal Dis 2008;10 Suppl 3:1-7.

2. Perry WB, Dykes SL, Buie WD, Rafferty JF; Standards Practice Task Force of the American Society of Colon and Rectal Surgeons. Practice parameters for the management of anal fissures 
(3rd revision). Dis Colon Rectum 2010;53:1110-5.

3. Altomare DF, Binda GA, Canuti S, Landolfi V, Trompetto M, Villani RD. The management of patients with primary chronic anal fissure: a position paper. Tech Coloproctol 2011;15:135-41.

4. Garg P, Garg M, Menon GR. Long-term continence disturbance after lateral internal sphincterotomy for chronic anal fissure: a systematic review and meta-analysis. Colorectal Dis 2013;15: e104-17.

5. García-Granero E, Sanahuja A, García-Botello SA, Faiz O, Esclápez $\mathrm{P}$, Espí A, et al. The ideal lateral internal sphincterotomy: clinical and endosonographic evaluation following open and closed internal anal sphincterotomy. Colorectal Dis 2009;11:502-7.

6. Renzi A, Izzo D, Di Sarno G, Talento P, Torelli F, Izzo G, et al. Clinical, manometric, and ultrasonographic results of pneumatic balloon dilatation vs. lateral internal sphincterotomy for chronic anal fissure: a prospective, randomized, controlled trial. Dis Colon Rectum 2008;51:121-7.

7. Pelta AE, Davis KG, Armstrong DN. Subcutaneous fissurotomy: a novel procedure for chronic fissure-in-ano. a review of 109 cases. Dis Colon Rectum 2007;50:1662-7.

8. Schornagel IL, Witvliet M, Engel AF. Five-year results of fissurectomy for chronic anal fissure: low recurrence rate and minimal effect on continence. Colorectal Dis 2012;14:997-1000.

9. Abramowitz L, Bouchard D, Souffran M, Devulder F, Ganansia R, Castinel A, et al. Sphincter-sparing anal-fissure surgery: a 1-year prospective, observational, multicentre study of fissurectomy with anoplasty. Colorectal Dis 2013;15:359-67.

10. Magdy A, El Nakeeb A, Fouda el Y, Youssef M, Farid M. Compar- ative study of conventional lateral internal sphincterotomy, V-Y anoplasty, and tailored lateral internal sphincterotomy with $\mathrm{V}-\mathrm{Y}$ anoplasty in the treatment of chronic anal fissure. J Gastrointest Surg 2012;16:1955-62.

11. Lambe GF, Driver CP, Morton S, Turnock RR. Fissurectomy as a treatment for anal fissures in children. Ann R Coll Surg Engl 2000;82:254-7.

12. Jorge JM, Wexner SD. Etiology and management of fecal incontinence. Dis Colon Rectum 1993;36:77-97.

13. Patel SD, Oxenham T, Praveen BV. Medium-term results of anal advancement flap compared with lateral sphincterotomy for the treatment of anal fissure. Int J Colorectal Dis 2011;26:1211-4.

14. Leong AF, Seow-Choen F. Lateral sphincterotomy compared with anal advancement flap for chronic anal fissure. Dis Colon Rectum 1995;38:69-71.

15. Mousavi SR, Sharifi M, Mehdikhah Z. A comparison between the results of fissurectomy and lateral internal sphincterotomy in the surgical management of chronic anal fissure. J Gastrointest Surg 2009;13:1279-82.

16. Hancke E, Rikas E, Suchan K, Völke K. Dermal flap coverage for chronic anal fissure: lower incidence of anal incontinence compared to lateral internal sphincterotomy after long-term followup. Dis Colon Rectum 2010;53:1563-8.

17. Zimmerman DD, Gosselink MP, Hop WC, Darby M, Briel JW, Schouten WR. Impact of two different types of anal retractor on fecal continence after fistula repair: a prospective, randomized, clinical trial. Dis Colon Rectum 2003;46:1674-9. 